\title{
Evaluation of neuroprotective and anti- amnesic effects of Elaeagnus umbellata Thunb. On scopolamine-induced memory impairment in mice
}

Nausheen Nazir ${ }^{1 *}$ (D, Muhammad Zahoor ${ }^{1}$, Mohammad Nisar ${ }^{2}$, Nasiara Karim $^{3}$, Abdul Latif ${ }^{4}$, Sajjad Ahmad ${ }^{5}$ and Zia Uddin 6

\begin{abstract}
Background: Elaeagnus umbellata is abundantly found in Himalayan regions of Pakistan which is traditionally used to treat various health disorders. However, the experimental evidence supporting the anti-amnesic effect is limited. Therefore the study was aimed to evaluate the prospective beneficial effect of E. umbellata on learning and memory in mice.
\end{abstract}

Objectives: To assess neuroprotective and anti-amnesic effects of $E$. umbellata fruit extracts and isolated compounds on the central nervous system.

Methods: Major phytochemical groups present in methanolic extract of E. umbellata were qualitatively determined. The total phenolic and flavonoid contents were also determined in extract/fractions of E. umbellata. On the basis of in vitro promising anticholinesterases (AChE \& BChE) and antioxidant activities observed for CHF. Ext and isolated compound-I (Chlorogenic acid = CGA), they were further evaluated for learning and memory in normal and scopolamine-induced cognitive impairment in mice using memory behavioral tests such as the $Y$ maze and Novel object recognition using standard procedures. The test sample were further assessed for in vivo anticholinesterases (AChE \& BChE) and DPPH free radical scavenging activities in mice brain sample and finally validated by molecular docking study using GOLD software.

Results: The extract/fractions and isolated compounds were tested for their anticholinesterase and antioxidant potentials. The CHF. Ext and CGA showed maximum \% inhibition of tested cholinesterases and free radicals. The CHF. Ext and CGA reversed the effects of scopolamine in mice. The CHF. Ext and CGA significantly increased the alternate arm returns and \% spontaneous alteration performance while escape latency times (second) significantly decreased in Y maze test. The CHF. Ext and CGA significantly increased the time spent with novel object and also increased the discrimination index in the Novel object recognition test. Furthermore, molecular docking was used to validate the mechanism of cholinesterases inhibition of isolated compounds.

(Continued on next page)

\footnotetext{
*Correspondence: nausheen.nazir@uom.edu.pk

${ }^{1}$ Department of Biochemistry, University of Malakand, Chakdara Dir (L), Khyber Pakhtunkhwa, Pakistan

Full list of author information is available at the end of the article
}

(C) The Author(s). 2020 Open Access This article is licensed under a Creative Commons Attribution 4.0 International License, which permits use, sharing, adaptation, distribution and reproduction in any medium or format, as long as you give appropriate credit to the original author(s) and the source, provide a link to the Creative Commons licence, and indicate if changes were made. The images or other third party material in this article are included in the article's Creative Commons licence, unless indicated otherwise in a credit line to the material. If material is not included in the article's Creative Commons licence and your intended use is not permitted by statutory regulation or exceeds the permitted use, you will need to obtain permission directly from the copyright holder. To view a copy of this licence, visit http://creativecommons.org/licenses/by/4.0/. The Creative Commons Public Domain Dedication waiver (http://creativecommons.org/publicdomain/zero/1.0/) applies to the data made available in this article, unless otherwise stated in a credit line to the data. 


\begin{abstract}
(Continued from previous page)
Conclusion: The data obtained from behavioral and biochemical studies (AChE/BChE and DPPH/ABTS inhibition) have shown that $E$. umbellata possessed significant memory enhancing potency. These results suggest that $E$. umbellata extract possess potential antiamnesic effects and amongst the isolated compounds, compound I could be more effective anti-amnesic therapeutics. However, further studies are needed to identify the exact mechanism of action.
\end{abstract}

Keywords: Elaeagnus umbellata, Amnesia, Cholinesterases, Scopolamine, Y-maze test, Novel object recognition test, Molecular docking

\section{Background}

Alzheimer's disease (AD) is a neurodegenerative fatal brain disorder that causes both physical and mental deterioration in human leading to death of an individual suffering from this disease. According to World Alzheimer's organization report 2015, globally the number of individuals affected by $\mathrm{AD}$ and other forms of dementia are about 46.85 million. They have also predicted that this number will be doubled by 2030 which would further increase to three folds of the existing level by 2050 $[1,2]$. Clinically, Alzheimer's disease can be characterized by progressive memory deficits, inappropriate behaviour, and cognitive dysfunctions such as learning impairment and amnesia being the most remarkable age-related alterations [3]. Pathologically, AD has been characterized by loss of the cholinergic neurons, extracellular deposition of $\beta$-amyloid peptide and low level of neurotransmitter acetyl choline (ACh) [4-6]. Acetyl cholinesterase $(\mathrm{AChE})$ and butyryl cholinesterase $(\mathrm{BChE})$ enzymes cause degradation of ACh which produces cholinergic deficits. Inhibitions of these two enzymes are considered as a best strategy to treat $\mathrm{AD}$, dementia, and Parkinson's disease [7]. However, the ultimate cause of $\mathrm{AD}$ is still a mystery, there are several hypothesis about its causes [8]. Amnesia is a condition of severe disruption of memory from the impairment of the hypothalamus, thalamus and the surrounding cortical structures without deficits in cognition, attention, awareness or judgment [9-11]. Scientists all over the world are exploring novel compounds which could attenuate the neurological disorders and amnesia that may probably be due to the vulnerability of the brain cells to increased production of free radicals [12, 13].

Antioxidant remedy has proved to be successful in the amelioration of cognitive dysfunction and behavioral insufficiency in patients with mild to moderate AD. Natural products are the major source of antioxidants which delay the development of $\mathrm{AD}$ and attenuate neuronal cell death $[14,15]$.

Medicinal plants received much attention due to the presence of important bioactive secondary metabolites, such as alkaloids, terpenoids, carotenoids, poly phenols, and flavonoids $[16,17]$. Among the medicinal plants $E$. umbellata Thumb. a wild spiny branched shrub that belongs to Elaeagnaceae family, is a very important plant as they have berries fruit [18]. Apart from their edibility, different parts of the E. umbellata have been used in folk medicine as anti-inflammatory, muscle relaxant, antipyretic, analgesic, astringent, antiulcer, antidiabetic, anti-diarrheal, as a tonic to cure coughs and pulmonary complications [19-23]. Several studies have shown that regular consumption of polyphenolic rich barriers fruits are associated with delayed Alzheimer's disease and other brain related disorders because of their antioxidant, anti-inflammatory, and anti-proliferative properties [24-26].

In this investigational study, an attempt has been made to establish a link between the neuroprotective beneficial effects of berries with its phytoconstituents. Chlorogenic acid and ellagic acid are the polyphenolic compounds that have shown strong neuroprotective and cognitive enhancement effects on scopolamine-induced amnesia and anti-oxidative activities in animal models [27-29]. Keeping in mind, the mentioned properties of isolated compound, chlorogenic acid it was expected that it could be a leading therapeutic having impact on memory disorders and would have a positive impact on human health which would be an effective remedy for the treatment of degenerative diseases.

\section{Methods \\ Chemicals}

All the chemical used were of analytical grade with the exception of HPLC solvents that were of HPLC grade. The DTNB (5, 5-dithio-bis-nitrobenzoic acid), Quercetin, Streptozotocin, PNPG, Galantamine (Lycoris Sp.), Acetyl cholinesterase (Electron-eel Type, VI-S), butyryl cholinesterase (lot No SLBPO912V), 3,5- Dinitrosalicylic acid (lot No D2401QEI), DPPH, ABTS, Ascorbic acid, Acetylthiocholine-iodide, Butyrylthiocholine-iodide, Gallic acid \& Folin-Ciocalteu regent were obtained from Sigma-Aldrich, Germany.

\section{Plant material collection}

The fruits of E. umbellata Thunb. were collected from the hilly areas of Kalam, Malakand Division, Khyber 
Pakhtunkhwa, Pakistan, in August-September 2016. The plant sample was identified by plant taxonomist; Prof. Mehboob-ur-Rahman, PGC. Swat, Khyber Pakhtunkhwa, Pakistan. The plant specimens were deposited in the Botanical Garden Herbarium, University of Malakand, Pakistan with voucher number BGH.UOM.154. The plant variety selected was a wild one therefore, permission was taken from Divisional Forest Officer, Kalam and Local administration.

Extraction, fractionation and isolation of pure compounds E. umbellata Thunb. fruits extract preparation and fractionation were carried out according to the method described in a previously published research article with slight modification [19]. About $10 \mathrm{~kg}$ of dried fruits were crushed through mechanical grinder into fine powders which were then macerated in $80 \%$ methanol for 14 days with periodical shaking. Filtration was carried out through muslin cloth followed by Whattman filter paper. The filtrates were converted into a semisolid mass under reduced pressure in the rotary evaporator (Schwabach: 4000; Heidolph-Laborota-Germany) at $40{ }^{\circ} \mathrm{C}$. The semisolid mass was then solidified (750 g end yield) in open air. The solvent-solvent extraction method was used to get different fractions using different solvents starting from a low to high polarity. The final yield of $n$-hexane (Hex.Ext), chloroform (CHF.Ext), ethyl acetate (EtAc.Ext), $n$ - butanol (But.Ext) and aqueous (Aq.Ext) fractions were 95, 210, 115, 90 and 220 g respectively. Being the most active fraction biologically (in-vitro analysis results), the CHF. Ext fraction was subjected further to isolation of bioactive compounds in pure state. The CHF. Ext fraction was mixed with silica gel slurry and then allowed to dry in air. The sample loaded silica was then carefully loaded to large silica gel column with internal diameter of $10 \mathrm{~cm}$ packed height $50 \mathrm{~cm}$ using a gradient of increasing polarity with total $n$-hexane to total ethyl acetate as mobile phase. The effluents of columns were separated into 15 fractions on the basis of TLC analysis for random isolation of compounds. Finally the narrow pen column was used to separate the active sub fraction and collect it into small vials. The effluents of pencil column were spotted on TLC plates with suitable solvent system. Fraction 11 (12.0 g) was reseparated by silica gel column chromatography in solvent system of $n$-hexane and ethyl acetate (3:7) to afford pure compound-I (11.2 mg). Fraction 9 (4.25 g) was reseparated by silica gel column chromatography in solvent system of $n$-hexane and ethyl acetate (2:8) to afford pure compounds-II $(32.4 \mathrm{mg})$. Fraction 7 ( $8.0 \mathrm{~g})$ give pure compounds-III (20 mg) in solvent system of $n$-hexane and ethyl acetate (4:6), while fraction 4 (11.22 mg) was re-separated by silica gel column chromatography in solvent system of $n$-hexane and ethyl acetate (6:4) to afford pure compounds-IV $(4.20 \mathrm{mg})$. The vials with identical $R_{f}$ values were mixed together and purified. After purification, the compound were characterized through different spectroscopic techniques like FTIR, HNMR, 13CNMR and Mass spectrometry. The purified compounds were screened for in-vitro anticholinesterase and in-vivo anti-amnesic activities.

\section{Preliminary screening of phytochemicals}

Hydro methanolic extract (Met.Ext) of E. umbellata fruit was investigated to identify major phytoconstituents like flavonoids, alkaloids, glycosides, terpenoids, anthraquinone, tannins and pigments using reported assays [30].

\section{Estimation of total phenolic content}

Previously reported methods [31, 32] were used to estimate the total phenolic contents (TPC) in extract/ fractions like hydro methanolic extract, $n$-hexane, chloroform, ethyl acetate, $n$-butanol and aqueous fraction of E. umbellata fruit. The extract/fractions samples $(100 \mu \mathrm{L})$, distilled water $(500 \mu \mathrm{L})$, Folin-Ciocalteu reagent $(100 \mu \mathrm{L})$ and $1000 \mu \mathrm{L}$ Sodium Carbonate (7\%) were mixed and allowed to stand for $90 \mathrm{~min}$ and finally at $760 \mathrm{~nm}$ absorbance was recorded through UVSpectrophotometer against the blank solution containing the extraction solvent instead of the sample. Calibration curve was drawn for standard Gallic acid as well. From calibration curve, the TPC in samples were calculated and reported as $\mathrm{mg}$ GAE/g of dry sample averaged from 3 parallel measurements.

\section{Estimation of total flavonoid contents}

According to previously reported methods [31, 32], the total flavonoid contents (TFC) was measured as mg QE/ g of dry samples of extract/fractions like hydro methanolic extract, $n$-hexane, chloroform, ethyl acetate, $n$-butanol and aqueous fraction of $E$. umbellata fruit. A calibration curve was drawn for different dilution of standard quercetin. From each sample dilutions $100 \mu \mathrm{L}$ were taken and mixed with $500 \mu \mathrm{L}$ distilled water, $100 \mu \mathrm{L}$ Sodium nitrate (5\%), $150 \mu \mathrm{L}$ Aluminium chloride $(10 \%)$ and $200 \mu \mathrm{L}$ Sodium hydroxide $(1 \mathrm{M})$. After $5 \mathrm{~min}$ absorbance were recorded at $510 \mathrm{~nm}$ by UVSpectrophotometer against a blank containing extraction solvent. All tests were achieved in triplicate.

\section{In-vitro anti-cholinesterase assay}

Ellman assay [33] was used to evaluate E. umbellata fruit extracts and isolated compounds for their anticholinesterase potentials. About $205 \mu \mathrm{L}$ extract/compound solutions and $5 \mu \mathrm{L}$ of $\mathrm{AChE}(0.03 \mathrm{U} / \mathrm{mL}) / \mathrm{BChE}(0.01 \mathrm{U} /$ $\mathrm{mL})$ along with catalyst DTNB $(5 \mu \mathrm{L})$ were taken in a cuvette and kept at $30^{\circ} \mathrm{C}$ in hot water bath for $15 \mathrm{~min}$. After $15 \mathrm{~min}$ of incubation acetylthiocholine iodide or 
butyrylthiocholine iodide were added as a substrate $(5 \mu \mathrm{L})$ to the mixture that resulted in yellow colouration (5-Thio-2-nitro benzoate anion colour). Then the absorbance was recorded at $412 \mathrm{~nm}$ through double beam spectrophotometer (Thermo electron-corporation; USA). As a negative control solution all the above mentioned components except extracts and isolated compounds were mixed in the mentioned order. Donepezil was used as a positive control. The same procedure mentioned above was used for reaction mixture of positive control and absorbance was measured at 412 $\mathrm{nm}$. For each sample absorption was recorded for $4 \mathrm{~min}$. Percent enzyme activity and inhibition potential of both enzymes were measured by the following formulas:

$$
\begin{aligned}
& V=\Delta \mathrm{Abs} / \Delta t \\
& \text { \%enzyme activity }=\frac{V}{V \max } \times 100 \\
& \text { \%enzyme inhibition }=100-\% \text { enzyme activity }
\end{aligned}
$$

$\mathrm{V}$ is inhibitor dependent rate of reaction while, Vmax is inhibitor independent rate of reaction.

\section{DPPH (2, 2-diphenyl, 1, picrylhydrazyl) scavenging assay} Brand-Williams assay [34] was used to find out DPPH free radical scavenging activity of isolated compounds of E. umbellata. About $24 \mathrm{mg}$, DPPH was dissolved in 100 $\mathrm{mL}$ methanol. Compounds solutions $(1 \mathrm{mg} / \mathrm{mL})$ were also prepared in methanol. Working solutions were prepared using serial dilutions in the concentrations range of $1000,500,250,125,62.5$ and $31.05 \mu \mathrm{g} / \mathrm{mL}$. About 0.1 $\mathrm{mL}$ of each working dilution was mixed with DPPH (3.0 $\mathrm{mL}$ ) and incubated at $25^{\circ} \mathrm{C}$ for $30 \mathrm{~min}$. Absorbance was measured at $517 \mathrm{~nm}$ via UV-spectrophotometer (Thermo Electron Corporation: USA). Ascorbic acid was used as a standard. Results are presented as Mean \pm SEM that has been calculated using the formula:

$$
\begin{aligned}
& \text { \%DPPH Scavenging potential } \\
& =\frac{\text { standard absorbance-sample absorbance }}{\text { standard absorbance }} \\
& \times 100 \quad
\end{aligned}
$$

\section{ABTS (2, 2'-Azino-bis (3-ethylbenzothiazoline-6-sulfonic acid) scavenging assay}

According to the previously reported $\mathrm{Re}$ et al. [35] method antioxidant potential of isolated compounds of E. umbellata were determined against ABTS free radicals. ABTS $(7 \mathrm{mM})$ and potassium persulfate $(2.45 \mathrm{mM})$ solutions were mixed thoroughly and were incubated overnight in dark for the production of ABTS free radical. The absorption of this mixture was adjusted to 0.7 at $745 \mathrm{~nm}$ by adding methanol. About $300 \mu \mathrm{L}$ compounds working dilutions and $3.0 \mathrm{~mL}$ ABTS solutions were mixed and incubated for $6 \mathrm{~min}$. Finally the absorbance was measured via UV spectrophotometer. Ascorbic acid was used as positive control. \% ABTS scavenging potential was measured using eq. 4 .

\section{Animals}

A total of 144 healthy Swiss male albino mice (25-30 g body weight) were obtained from National Institute of Health Islamabad Pakistan. All the animals were maintained in the animal house of the Department of Pharmacy, University of Malakand. The mice were housed in groups of six mice each in individual cages. All the animals were provided water and normal pellet diet and were kept under normal laboratory conditions with $12 \mathrm{~h}$ of light-dark cycle. All the animal procedures were conducted according to the UK animal scientific procedure act (1986) and approval was taken from the Departmental Animal Ethical Committee (DAEC/ PHARM/2019/1).

\section{Acute toxicity studies of the CHF. Ext fraction and isolated compound-I}

All animals were then treated orally with different doses of CHF. Ext (100, 200, 400, 500, 1000, 1500 and 2000 $\mathrm{mg} / \mathrm{kg}$ body weight) and compound-I at doses of 50 , $100,150,200,250,300 \mathrm{mg} / \mathrm{kg}$ body weight. Immediately after dosing, the mice were observed continuously for 4 $\mathrm{h}$ for symptoms of toxicity such as motor activity, convulsions, muscle spasm, tremors, sedation, lacrimation, hypnosis, diarrhoea, salivation, and loss of righting reflex. Mice were then kept under observation up to $72 \mathrm{~h}$ for any mortality. The CHF. Ext remained safe and nontoxic up to $2000 \mathrm{mg} / \mathrm{kg}$ and compound-I up to $300 \mathrm{mg} /$ $\mathrm{kg}$ body weight dose range. Therefore, according to OECD guidelines, CHF. Ext at dose $200 \mathrm{mg} / \mathrm{kg}$ body weight that was $1 / 10$ th of $2000 \mathrm{mg} / \mathrm{kg}$ and compound-I at dose $30 \mathrm{mg} / \mathrm{kg}$ body weight that was $1 / 10$ th of 300 $\mathrm{mg} / \mathrm{Kg}$ dose (maximum tested dose) was selected to evaluate the in-vivo anti-amnesic effect [36].

\section{Experimental design of inducing amnesia in mice}

After the acclimatization period, in scopolamine-induced amnesia test the Albino male mice were randomly divided into six groups $(n=6)$ to study the effect of CHF. Ext and seven groups $(n=6)$ for compound-I (CGA). The doses of tested solutions of CHF. Ext have been presented in Table 1 while that of compound-I in Table 2. The treatments were continued for 8 days. In the Ymaze and Novel object recognition tests, scopolamine (1 $\mathrm{mg} / \mathrm{kg}$, i.p.) was given to the different groups only on the 8th day, $30 \mathrm{~min}$ after the respective treatments, to 
Table 1 Experimental design for CHF. Ext tretament groups used in the study

\begin{tabular}{llll}
\hline Group & Group Category & Treatment given & Route \\
\hline I II & Normal control & Normal saline $(8 \mathrm{mg} / \mathrm{kg})$ & p.o. \\
III & Negative control & scopolamine $(1 \mathrm{mg} / \mathrm{kg})$ & i.p. \\
IV & Positive control & Donepezil $(2 \mathrm{mg} / \mathrm{kg})+$ scopolamine $(1 \mathrm{mg} / \mathrm{kg})$ & p.o, i.p \\
V & Treatment group & CHF. Ext $(50 \mathrm{mg} / \mathrm{kg})+$ scopolamine $(1 \mathrm{mg} / \mathrm{kg})$ & p.o \\
VI & Treatment group & CHF. Ext $(100 \mathrm{mg} / \mathrm{kg})+$ scopolamine $(1 \mathrm{mg} / \mathrm{kg})$ & p.o \\
\hline
\end{tabular}

CHF.Ext, Chloroform fraction; p.o., Per oral; i.p., Intraperitoneal

induce cognitive deficit in mice. One hour after administration of the drugs all animals were subjected to Ymaze and Novel object recognition test following standard procedure [10].

\section{Y-maze test for spontaneous alternation}

The Y-Maze test was designed to evaluate the short term memory in experimental mice using reported procedure [37]. Y-maze apparatus is $\mathrm{Y}$ shaped with three arms of equivalent size, labelled as $\mathrm{A}, \mathrm{B}$, and $\mathrm{C}$. Each arm was $20 \mathrm{~cm}$ long, $6 \mathrm{~cm}$ wide and $15.5 \mathrm{~cm}$ high and was oriented at an angle of $120^{\circ}$ from the other two. For each animal the $\mathrm{Y}$ maze testing was carried out for $5 \mathrm{~min}$. Mice were placed in one arm, and the order and number of arm entries were recorded. An arm entry was considered to be complete when the hind paws of the mice was completely inside a given arm while alternation was defined as consecutive entries by a mouse into the three different arms. The arena was cleaned using $70 \% \mathrm{v} / \mathrm{v}$ ethanol between each trial to avoid olfactory cues. The escape latency (second) on day 1-5 were recorded for all animals. At the end of 5th day, the spontaneous alteration behavior study was conducted. In spontaneous alteration study, each animal was placed at the center of the Y-Maze apparatus and allowed to move freely through the maze. The series of arm entries were visually recorded. To start behavioral test the mice was set in one arm and recorded the number of arm entries, same arm returns (SAR), and alternate arm returns (AAR) were measured. Percent spontaneous alternation performance (SAP) was calculated by the following formula:

$$
\% S A P=\frac{\text { Active alterations (total alterations) }}{\text { Possible alterations (total arm entries) }}-2 \times 100
$$

\section{Novel object recognition test}

The detail methodology [36] published, was followed while performing the novel object recognition (NORT) test. NORT consisting of habituation, sample, and test phases. On the day before test, mice were allowed to explore the box (without any object) for $2 \mathrm{~min}$. On the day of test after habituation the sample phase was carried out $60 \mathrm{~min}$ after the last treatment on the 8th day. In sample phase each mouse was placed in an open field with two identical objects (plastic ball) for $5 \mathrm{~min}$. The mouse was then returned to its home cage. The apparatus was comprised of a white coloured plywood box $(40 \mathrm{~cm} \times 40 \mathrm{~cm} \times 66 \mathrm{~cm})$ with a network floors that could be effortlessly cleaned (with $70 \% \mathrm{v} / \mathrm{v}$ ethanol) after every trial. The apparatus was illuminated by a $60 \mathrm{~W}$ light suspended $50 \mathrm{~cm}$ over the crate. The arena and objects were cleaned with $70 \% \mathrm{v} / \mathrm{v}$ ethanol between trials to avoid olfactory cues. For short-term memory, the test phase was performed $5 \mathrm{~min}$ after the sample phase. In the test phase, each mouse was placed again in the open field in which one of the identical objects had been replaced with a novel object (plastic square). The location of the object was counterbalanced so that one half of the mice in each group saw the novel object on the left side of the box arena, and the other half saw the novel object on the right side of the box arena to eliminate bias of sides. NORT can also be used for encoding and retrieval

Table 2 Experimental design for compound-I (CGA) tretament groups used in the study

\begin{tabular}{llll}
\hline Group & Group Category & Treatment given & Route \\
\hline I & Normal control & Normal saline $(8 \mathrm{~mL} / \mathrm{kg})$ & p.o. \\
III & Negative control & Scopolamine $(1 \mathrm{mg} / \mathrm{kg})$ & i.p. \\
IV & Positive control & Donepezil $(2 \mathrm{mg} / \mathrm{kg})+$ scopolamine $(1 \mathrm{mg} / \mathrm{kg})$ & p.o. i.p. \\
$V$ & Treatment group & CGA $(1 \mathrm{mg} / \mathrm{kg})+$ Scopolamine $(1 \mathrm{mg} / \mathrm{kg})$ & p.o \\
VI & Treatment group & CGA $(3 \mathrm{mg} / \mathrm{kg})+$ scopolamine $(1 \mathrm{mg} / \mathrm{kg})$ & p.o \\
\hline
\end{tabular}

CGA, Chlorogenic acid; p.o., Per oral; i.p., Intraperitoneal 
of spatial memory (long-term memory). A wash-out period of 5 days was allowed before the NORT to assess long-term memory in mice [38]. The procedure was the same as that for short-term memory except that mice were presented in the test phase $24 \mathrm{~h}$ after the sample phase exposure. The time spent exploring each object in each phase was recorded manually using a stopwatch. A mouse was scored as exploring when its head was oriented towards the object within a distance of $2 \mathrm{~cm}$ or when the nose was in contact with the object. Parameters including the time (in seconds) spent exploring familiar (F) object, time (in seconds) spent exploring the novel $(\mathrm{N})$ object, and total time (in seconds) spent exploring both objects $(\mathrm{N}+\mathrm{F})$ were measured separately. Percentage of discrimination index (DI) was calculated by formula:

$$
\% D I=\frac{\mathrm{N}-\mathrm{F}}{\mathrm{N}+\mathrm{F}} \times 100
$$

\section{Isolation of frontal cortex and hippocampus}

Immediately after the Y-Maze test and NORT, all the animals were sacrificed by cervical dislocation before decapitation to provide each animal with a quick and painless death using previous procedure illustrated in schedule-1 of UK, animal scientific procedure act 1986. The frontal cortex (FC) and hippocampus (HC) were dissected out in ice cold $0.1 \mathrm{M}$ phosphate buffer saline ( $\mathrm{pH} 8.0)$. The tissues were weighed and $20 \mathrm{mg}$ tissue/mL homogenate of brain samples was prepared in phosphate buffer ( $\mathrm{pH} 8.0)$. The homogenates were centrifuged at $10,000 \mathrm{rpm}$ for $10 \mathrm{~min}$ at $4{ }^{\circ} \mathrm{C}$, and the resulting supernatant was used for the estimation of anti-cholinesterase activity following Ellman's [33] and antioxidants assays $[34,35]$.

\section{Molecular docking validation for anti-amnesic activity}

For theoretical study towards anticholinesterase activity, two dimensional structure of molecules were drawn on Chem Draw Professional 16.0 (PerkinElmer Inc.) and finally adapted to $3 \mathrm{D}$ conformations followed by energy minimizations using Chimera 1.13.1rc. Docking simulations were performed on GOLD (Genetic Optimizations for Ligands) software (GOLD suit 5.6.3, Cambridge Crystallographic Data Center) [39]. Gold score was selected as a fitness function for the ligand molecules. A search area of $6 \AA$ radius was fixed for docking simulations in the active sites of the reference ligands. Acetyl cholinesterase and butyryl cholinesterase (PDB ID: 4BDS) were selected as receptor enzymes with wellestablished crystal structures recovered from the website of Protein Data Bank (www.rcsb.org). These structures of protein were subsequently prepared by hydrogen addition and water and co-crystallized ligands elimination. Default settings were adopted for all parameters. Areas where reference ligands were bound to enzymes were designated as active sites. The HPLC detected and isolated compounds were docked into designated active gorges to see their possible interactions with different amino acids. Docking accuracy was also validated by redocking of the reference ligands. The different images (2D \& 3D) were visualized and processed by using Discovery Studio Visualizer software [40].

\section{Statistical analysis}

All in-vitro experiments were performed in three replicates by applying two way ANOVA followed by Bonferroni Post-test to determine the values of $\mathrm{P}$. The results were represented as Mean with SEM.

For in vivo analysis Student's t-test, one way ANOVA followed by Dunnett's posthoc multiple comparisons \& two way ANOVA followed by Bonferroni Post-test were used to determine the values of $\mathrm{P}$. $P<0.05$ were considered as significant. Different animals groups: Scopolamine treated group, Donepezil treated group (standard control), Normal saline treated group, CGA \& CHF. Ext treated group (test control) were used in the in vivo study. Values were significantly different in comparison to scopolamine treated group. ${ }^{* * *}: p<0.001,{ }^{* *}: p<0.01, *: p<0.05$ and $n s$ : Values not significantly different in comparison to Scopolamine treated group.

\section{Assessment of $\mathrm{IC}_{50}$ values}

Linear regression was used to calculate $\mathrm{IC}_{50}$ from \% inhibition of data of AChE and BChE by different concentration of test samples using Excel program 2007.

\section{Regression $(y)$ and linear correlation $\left(\mathrm{R}^{2}\right)$}

Regression $(y)$ and linear correlation $\left(\mathrm{R}^{2}\right)$ were used to determine TPC, TFC, the antioxidant and enzyme inhibition potentials of samples using Excel 2007.

\section{Results}

Preliminary screening of phytochemicals

E. umbellata fruit Met. Ext give positive results for preliminary major phytochemical groups that are presented in Table 3.

\section{Total phenolic content (TPC)}

Standard Gallic acid curve was constructed by preparing the dilutions $20,40,60,80$ and $100 \mathrm{mg} / \mathrm{mL}$ to estimate the TPC in E. umbellata fruit samples using graphical regression method (Fig. 1a). Comparatively higher TPC contents were estimated in almost all fractions than the control sample $(1.25 \pm 0.55 \mathrm{mg}$ GAE / g of dry sample) (Table S1). CHF. Ext and EtAc. Ext fractions (56.97 \pm 
Table 3 Preliminary qualitative phytochemical screening of Met. Ext from Elaeagnus umbellata Thunb. fruit

\begin{tabular}{lllll}
\hline S. No & Phytochemical groups & Reagents used & Analyses & Results \\
\hline $\mathbf{1}$ & Alkaloids & Dragendorff's & Orange red color precipitate & Yellow color and after HCL addition becomes colorless \\
$\mathbf{2}$ & Flavonoids & Ferric-chloride & Formation of red to brown layer \\
$\mathbf{3}$ & Glycosides & Keller Killiani & Brownish-green precipitate \\
$\mathbf{4}$ & Tannins & Gelatin & Reddish brown boundary \\
$\mathbf{5}$ & Triterpenoids & Liebermann Burchard & Formation of reddish color \\
$\mathbf{6}$ & Anthraquinones & Bontrager's & + \\
+
\end{tabular}

0.77 and $49.15 \pm 1.05 \mathrm{mg}$ GAE / g of dry sample) showed highest percentage of total phenolic contents amongst the samples.

\section{Total flavonoid contents (TFC)}

To estimate the TFC in E. umbellata fruit hydro methanolic extract and various fractions, a regression curve of standard quercetin was constructed by preparing the dilutions 20,40, 60, 80 and $100 \mathrm{mg} / \mathrm{mL}$ and the regression equation was used for TFC estimation. The estimated contents are graphically presented in Fig. 1b. Highest total flavonoid content was present in CHF. Ext and EtAc. Ext fractions (75.53 \pm 0.44 and $63.49 \pm 1.03 \mathrm{mg} \mathrm{QE} / \mathrm{g}$ of dry sample respectively; Table S1). The results are statistically significant in comparison with the control $(1.59 \pm 0.25 \mathrm{mg} Q E / g$ of dry extract sample).
In vitro cholinesterase inhibitory potential of $E$. umbellata Thunb. Fruit extract/fractions and isolated compounds Cholinesterase (AChE and BChE) inhibition by E. umbellata Thunb. Extract/fractions were determined at various concentrations and are presented in Figs. 1c to $\mathrm{f}$ (Table S2). Among different fractions, CHF. Ext and EtAc. Ext showed highest percent activities against AChE $(87 \pm 1.2$ and $84 \pm 1.0)$ with $\mathrm{IC}_{50}$ values of 33 and $55 \mu \mathrm{g} / \mathrm{mL}$ respectively (Fig. 1c). Similarly, CHF. Ext and EtAc. Ext fractions also showed highest percent inhibition against, BChE which were $86 \pm 0.3$ and $82 \pm 0.5$ with $\mathrm{IC}_{50}$ values 35 and $58 \mu \mathrm{g} / \mathrm{mL}$ respectively (Fig. 1d). Methanolic extract and subsequent fractions showed concentration dependent activities. Donepezil have been used as positive control that showed \% inhibition of $92 \pm 0.3$ with $\mathrm{IC}_{50}$ of $28 \mu \mathrm{g} / \mathrm{mL}$.

Similarly, the \%AChE and \%BChE inhibition potential of isolated compounds (I-IV) are presented in Fig. 1e \&

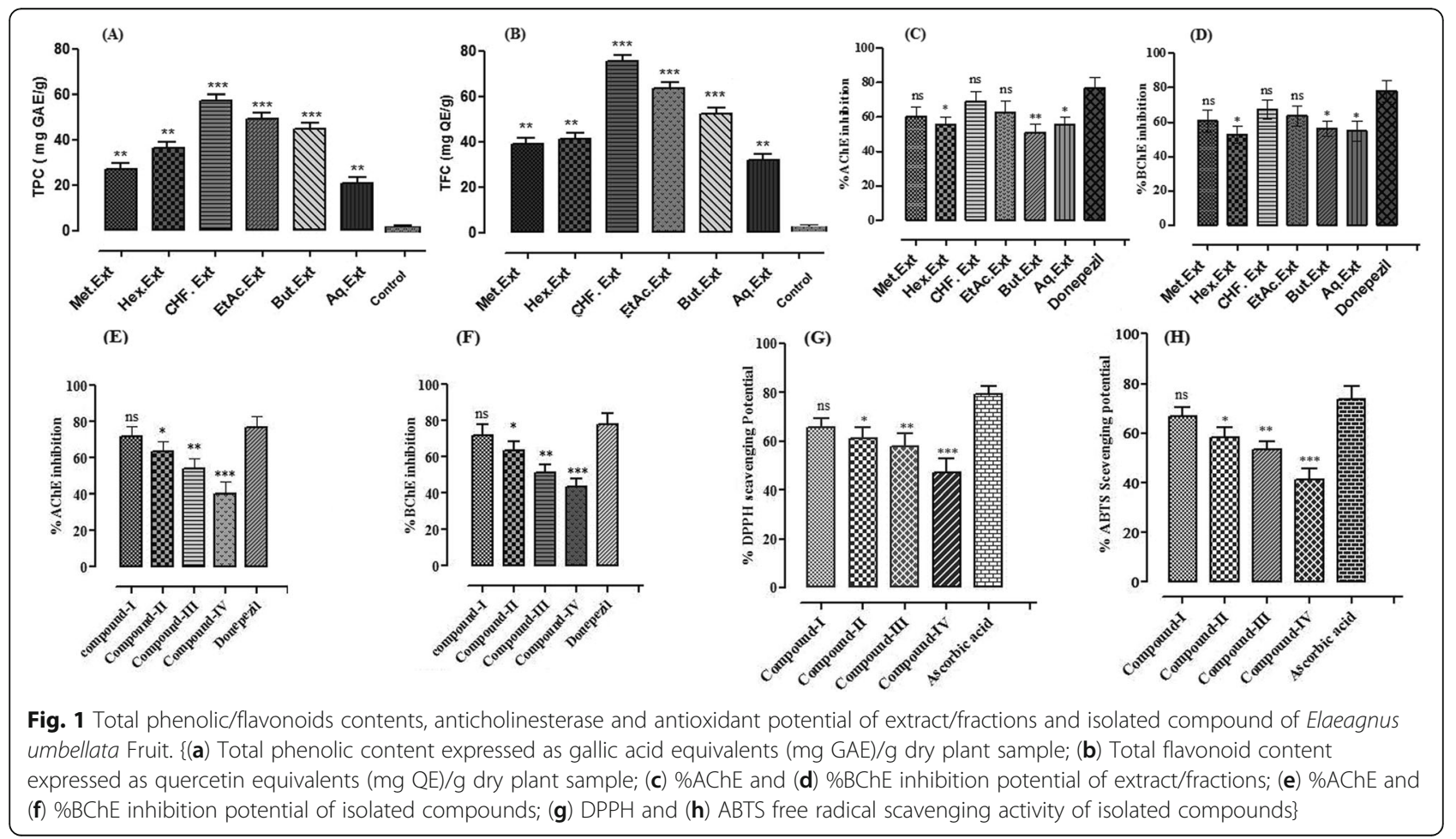


f (Table S3). Compound I showed prominent inhibition against $\mathrm{AChE}(90 \pm 0.2)$ with $\mathrm{IC}_{50}$ value $31 \mu \mathrm{g} / \mathrm{mL}$. While, compound III, II and IV showed \% inhibition of $76 \pm 2.1$, $81 \pm 0.5$, and $66 \pm 1.2 \mu \mathrm{g} / \mathrm{mL}$ with $\mathrm{IC}_{50}$ values 45,59 and $92 \mu \mathrm{g} / \mathrm{mL}$ respectively (Fig. 1e). Interestingly the isolated compounds I and II showed comparable results with the standard drug donepezil that showed \% inhibition of $93 \pm$ 0.5 against $\mathrm{AChE}$ with $\mathrm{IC}_{50}$ value $25 \mu \mathrm{g} / \mathrm{mL}$.

Similarly, these compounds also showed high percent inhibition of BChE as well. Compound-I showed highest $\%$ inhibition of $88 \pm 0.2$ with $\mathrm{IC}_{50}$ of $32 \mu \mathrm{g} / \mathrm{mL}$ (Table S3). Other compounds like II, III, and IV showed \% inhibition of $80 \pm 0.5,66 \pm 1.5$, and $58 \pm 2.2$ with $\mathrm{IC}_{50}$ values 62,83 , and $115 \mu \mathrm{g} / \mathrm{mL}$ respectively (Fig. 1f). All the compound showed concentration dependent inhibitory activity.

\section{In vitro DPPH and ABTS scavenging potential of isolated compounds}

DPPH and ABTS inhibitory potential of compounds IIV are presented in Fig. $1 \mathrm{~g} \& \mathrm{~h}$. The results indicate that compound-I causes highest \% inhibition which was comparable to standard ascorbic acid. The results indicates that compound-I, causes significant \% inhibition potential with lowest $\mathrm{IC}_{50}$ values 35 and $38 \mu \mathrm{g} / \mathrm{mL}$ against DPPH and ABTS (Table S4).

Relationship of total phenolic/flavonoid contents of CHF. Ext versus cholinesterase inhibitory activity

Highest value of regression coefficient was obtained for $\operatorname{AChE}\left(R^{2}=0.988\right)$ and $B C h E\left(R^{2}=0.9779\right)$ inhibition when plotted against total phenolic contents of CHF. Ext (Figure S1B). Similarly, the correlation co-efficient for $\mathrm{AChE}$ and BChE inhibition verses total flavonoid contents were found to be 0.9301 and 0.9928 respectively (Figure S1D).

\section{Sstructural confirmation and characterization of isolated compounds \\ Compound-I: Chlorogenic acid}

Compound-I was isolated as amorphous colourless solid with molecular formula $\mathrm{C}_{16} \mathrm{H}_{18} \mathrm{O}_{9}$ on the base of its FAB-MS ion peak at $\mathrm{m} / \mathrm{z} 353.3$. The $\mathrm{R}_{f}$ value of compound-I is 0.45 in solvent system of $n$-hexane and ethyl acetate (3:7) while the melting point was $208-209^{\circ} \mathrm{C}$ and was soluble in methanol. The structural formula of compound-I is presented in Figure S2. The FTIR spectrum of compound-I is presented in Figure S3. Peak at $3647.39 \mathrm{~cm}^{-1}$ demonstrating the $-\mathrm{OH}$ group while $\mathrm{C}$ $\mathrm{H}$ bond stretching occurs at $3072.60 \mathrm{~cm}^{-1}$ peak. Aromatic nucleus has been detected from $\mathrm{C}=\mathrm{C}$ strong absorption bands at $1687.71 \mathrm{~cm}^{-1}$. The carbonyl functionality $(\mathrm{C}=\mathrm{O})$ occurs at $1639.49 \mathrm{~cm}^{-1}$. The broad peak at $3329.14 \mathrm{~cm}^{-1}$ representing the carboxyl group. The FAB-MS is represented in Figure S4. Compound-I ${ }^{1} \mathrm{H}$ -
NMR spectrum indicated singlet's at $4.18(\mathrm{dt}, \mathrm{J}=5.2,3.3$ $\mathrm{Hz}, 1 \mathrm{H}), 3.74(\mathrm{dd}, \mathrm{J}=8.6,3.2 \mathrm{~Hz}, 1 \mathrm{H}), 5.34$ (ddd, J = 9.6, 8.5, $4.4 \mathrm{~Hz}, 1 \mathrm{H}), 7.05(\mathrm{~d}, \mathrm{~J}=2.1 \mathrm{~Hz}, 1 \mathrm{H}), 6.78(\mathrm{~d}, \mathrm{~J}=8.1 \mathrm{~Hz}$, $1 \mathrm{H}), 6.95(\mathrm{dd}, \mathrm{J}=8.2,2.1 \mathrm{~Hz}, 1 \mathrm{H}), 7.56(\mathrm{~d}, \mathrm{~J}=15.9 \mathrm{~Hz}, 1 \mathrm{H})$ and $6.26(\mathrm{~d}, \mathrm{~J}=15.9 \mathrm{~Hz}, 1 \mathrm{H})$, corresponding to the $\mathrm{H}-3$, $\mathrm{H}-4, \mathrm{H}-5, \mathrm{H}-2^{\prime}, \mathrm{H}-5^{\prime}, \mathrm{H}-6^{\prime}, \mathrm{H}-7^{\prime}$ and $\mathrm{H}-8^{\prime}$ position, while the two $\mathrm{CH}_{2}$ protons ( $\alpha$ and $\beta$ ) were assigns multiplets at $\delta 2.04$ and 2.18 at position 2 and $\delta 2.24$ and 2.07 at position 6, respectively presented in Figure S5.

The ${ }^{13} \mathrm{C}$-NMR spectrum showed 16 signals, including eight methines, six quaternary and two $\mathrm{CH}_{2}$ carbons (Figure S6). ${ }^{13} \mathrm{C}$ NMR (126 MHz, MeOD) spectral data $\delta$ 76.11, 38.13, 71.27, 73.45, 71.89, 38.75, 176.99, 127.73, $115.19,146.68,149.46,116.45,122.97,147.04,115.17$, $168.65,48.98$ are presented in Table S5.

\section{Compound-Il: Ellagic acid}

The compound-II was isolated as tan to gray colour powder in solvent system n-hexane and ethyl acetate (2: 8) with molecular formula $\mathrm{C}_{14} \mathrm{H}_{6} \mathrm{O}_{8}$ on the base of its EIMS ion peak at $\mathrm{m} / \mathrm{z} 302.197 \mathrm{~g} / \mathrm{mol}$. The $\mathrm{R}_{f}$ value of compound-II is 0.57 while the melting point is $\geq 350{ }^{\circ} \mathrm{C}$ while boiling point is $364{ }^{\circ} \mathrm{C}$. The structural formula of compound-II is presented in Figure S2. ${ }^{1} \mathrm{H}$ NMR (Chloroform-d,500 MHz): $\delta=7.27(\mathrm{~s}, 2 \mathrm{H}$ ) the chemical shift of $\delta=7.27$ most probably represents the 2 protons attached on position 9 and 21 of the given structure, $\delta=$ $1.56 \mathrm{ppm}(\mathrm{s}, 2 \mathrm{H})$, the peak on the high chemical shift of 1.56 might be hydroxyl group protons at position 6 and 18 of the given structure, $0.08 \mathrm{ppm}(\mathrm{s}, 2 \mathrm{H})$ the singlet peak on very high chemical shift of 0.08 represents the proton of $-\mathrm{OH}$ group on position 8 and 20 of the given structure (Figure S7). ${ }^{13} \mathrm{C}$ NMR (Chloroform-d, 100 MHz): $\delta=108,51.8,48,42,37.6,13.7$ ppm (Figure S8). The EIMS of compound-II is given in Figure S9.

\section{Compound-III: Gallic acid}

The compound-III was isolated as Light yellowish white crystalline powder in solvent system n-hexane and ethyl acetate (4:6) with molecular formula $\mathrm{C}_{7} \mathrm{H}_{6} \mathrm{O}_{5}$ on the base of its EIMS ion peak at $\mathrm{m} / \mathrm{z} 170$ $\mathrm{g} / \mathrm{mol}$. The melting point of the compound is $260{ }^{\circ} \mathrm{C}$. The compound-III is soluble in ethanol, methanol, ether, glycerol, ethyl acetate and acetone with $\mathrm{R}_{f}$ value 0.35 . The structural formula of compound-III is given in Figure S2. ${ }^{1} \mathrm{H}$ NMR (Methanol-d $\mathrm{d}_{4}, 500$ $\mathrm{MHz}$ ): The proton NMR spectrum of the given compound has been provided in Figure S10. The exploited solvent was Methanol-d, which has been detected at $3.35 \mathrm{ppm}$ as given in the spectrum. $\delta=$ $7.08(\mathrm{~s}, 2 \mathrm{H})$ this singlet peak represents 2 protons attached on carbon number 3 and 10 of the given structure, $\delta=4.93 \mathrm{ppm}$ (br. s., $3 \mathrm{H}$ ) this broad singlet peak might be the proton attached as $-\mathrm{OH}$ group at 
carbon number 5, 7 and 9 of the identified structure. ${ }^{13} \mathrm{C}$ NMR (Methanol- $\mathrm{d}_{4}, 100 \mathrm{MHz}$ ): $\delta=169.0$, 145.0, 138.2, 120.6, $108.9 \mathrm{ppm}$ (Figure S11). The EIMS is represented in Figure S12.

\section{Compound-IV: Phloroglucinol}

The compound-IV was isolated as colourless to beige solid in solvent system $\mathrm{n}$-hexane and Ethyl acetate (6:4) with molecular formula $\mathrm{C}_{6} \mathrm{H}_{6} \mathrm{O}_{3}$ on the basis of its EIMS ion peak at $\mathrm{m} / \mathrm{z}$ 126.1. The melting point of the compound is $-219^{\circ} \mathrm{C}$ and $\mathrm{R}_{f}$ value is 0.39 . The compound is soluble in methanol, ethanol, and diethyl ether. The structural formula of compound-IV is given in Figure S2. The FTIR spectrum of compound-IV is presented in Figure S13. The absorption peaks at 3161.33 and $3479.58 \mathrm{~cm}^{-1}$ demonstrating the $-\mathrm{OH}$ group. Peak at $2887.44 \mathrm{~cm}^{-1}$ indicates $\mathrm{C}-\mathrm{H}$ stretching. Aromatic nucleus can be recognized by $\mathrm{C}=\mathrm{C}$ strong peak at $1612.49 \mathrm{~cm}^{-1}$. Band at $1739.79 \mathrm{~cm}^{-1}$ is due to functionality of 1,3 , 5 substituted benzene.

The NMR signals of compound-IV in methanol solvent is reported below: $1 \mathrm{H} \mathrm{NMR} \mathrm{(MeOD,} 300 \mathrm{MHz}) \delta$ $9.11(\mathrm{~s}, 11 \mathrm{H}), 5.83(\mathrm{~s}, 3 \mathrm{H}, \mathrm{CH})$ (Figure S14, Table S6) while $13 \mathrm{C}$ NMR (MeOD, $75 \mathrm{MHz}) \delta 160.0 \mathrm{ppm}(\mathrm{CH} 2)$, $95.5 \mathrm{ppm}(\mathrm{CH})$ (Figure S15, Table S6). The EIMS is shown in Figure S16.
In vivo antiamnesic potential of extract/fractions and isolated compounds

Effects of extract/fractions and isolated compounds in $Y$ maze test

$\mathrm{Y}$ maze test results are presented in Fig. 2. A nonsignificant $(p>0.05)$ decrease was observed in the total numbers of entries into arms of instrument both in scopolamine and treated groups (CHF.Ext and CGA) when compared to control group (Fig. 2a \& e). Returns to the same arms were significantly $(p<0.01)$ high in group treated with scopolamine in comparison to control group. CHF. Ext (200 mg/kg body weight), isolated compound CGA (10 and $30 \mathrm{mg} / \mathrm{kg}$ body weight) and donepezil $(2 \mathrm{mg} / \mathrm{kg})$ showed significant $(\mathrm{p}<0.01)$ reduction in the percentage of same arm returns comparable to scopolamine treated group (Fig. $2 b$ \& $\mathrm{f}$ ).

The CHF. Ext $(200 \mathrm{mg} / \mathrm{kg})$, isolated compound CGA (10 and $30 \mathrm{mg} / \mathrm{kg}$ body weight) and standard drug donepezil ( $2 \mathrm{mg} / \mathrm{kg}$ body weight) groups contrarily showed a significant $(* p<0.05 ; * * p<0.01)$ increase in the percentage of alternate arm returns as compared to scopolamine treated group where a significant decrease in the number of alternate arm returns was observed $(p<0.01$; Fig. $2 c \&$ g). At the end of 5th day of experimental cycle, spontaneous alteration behavior study was conducted (Fig. 2d \& h). In spontaneous alteration study, each animal was placed at the center of the Y-Maze apparatus and allowed to move freely through the maze in three trials

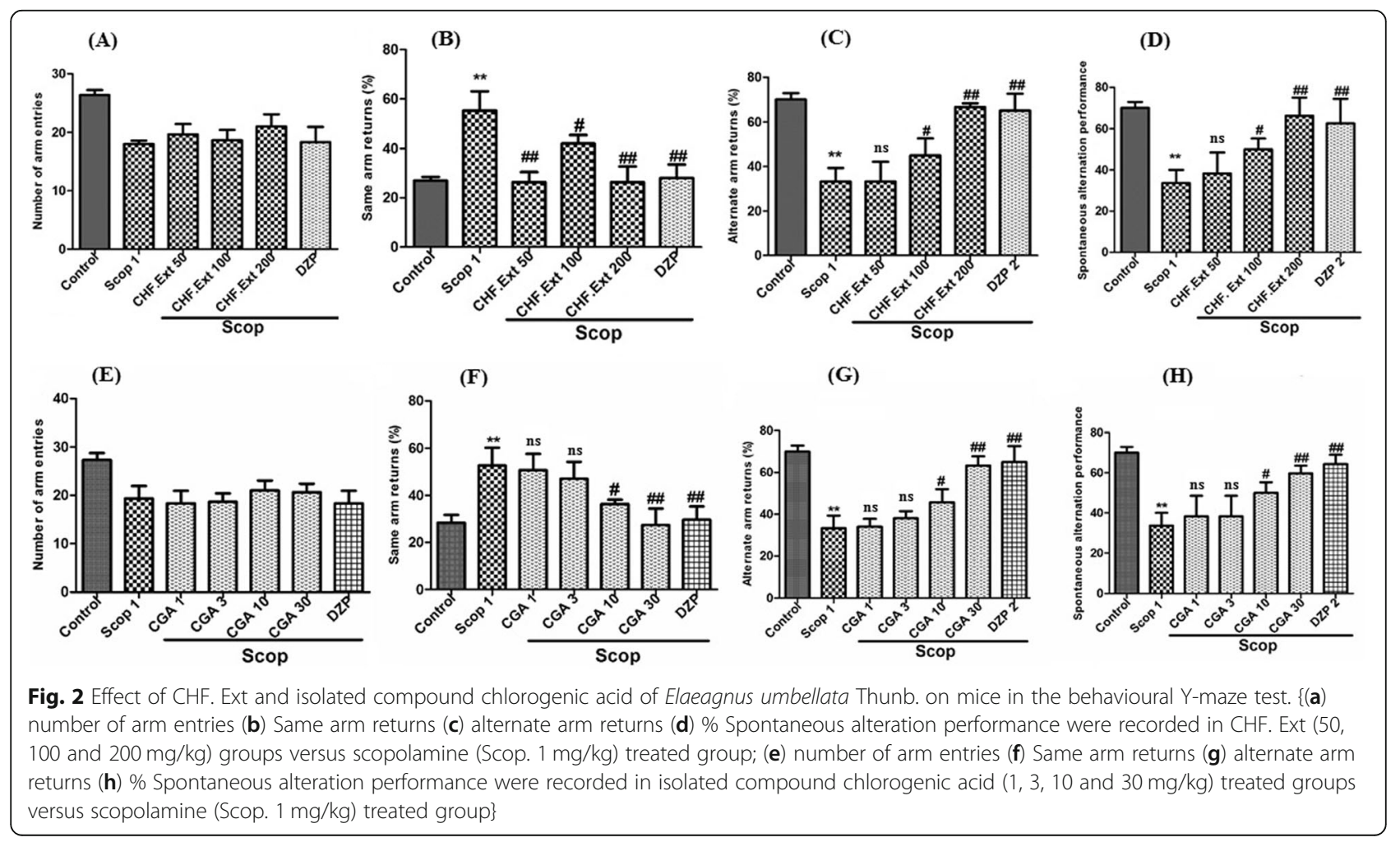


of 8-min session each. The series of arm entries were visually recorded. Dose dependent increase was also observed in \% spontaneous alteration performance (Fig. 2d $\& \mathrm{~h})$ which is significant $(p<0.01)$ for CHF. Ext $(200$ $\mathrm{mg} / \mathrm{kg}$ ) and comparable to the donepezil ( $2 \mathrm{mg} / \mathrm{kg}$ body weight). Results of Y-maze test conducted to determine escape latency (seconds) are given in Figure S17. Scopolamine treated group shown highest escape latency from day 1-5. The high escape latency time indicates poor cognitive function. Donepezil (standard control), normal control group, and treated groups (CHF.Ext \& CGA) were observed with significant decline $(p<0.001)^{* * * *}$ in escape latency over the whole experimental cycle that pointed towards the improved memory of the treated animals over the diseased control group.

\section{Effects of active extract/fractions and isolated compounds in novel object recognition test}

The results obtained with the novel object recognition test are shown in Fig. 3. To assess short term memory in the sample phase indicates that no significant difference in consuming time for exploration of two objects between CHF. Ext (Fig. 3a), CGA (Fig. 3d) treated groups, and scopolamine treated group. However, CHF. Ext (50, 100 and $200 \mathrm{mg} / \mathrm{kg}$ ), CGA (10 and $30 \mathrm{mg} / \mathrm{Kg}$ ) and donepezil $(2 \mathrm{mg} / \mathrm{kg})$ groups consume more time with novel object in the test phase as compared to scopolamine treated group $(* p<0.05, * p<0.01)$. Also, scopolamine $(1 \mathrm{mg} / \mathrm{kg})$ treated group spent more time with familiar object compared to novel object $(p<0.01)$ (Fig. 3b \& e). The \% Discrimination index (DI) was significantly high for CHF. Ext (50, 100 and $200 \mathrm{mg} / \mathrm{kg}$ ), CGA (10 and 30 $\mathrm{mg} / \mathrm{Kg})$, and donepezil $\left({ }^{*} p<0.05, * p<0.01\right)$ groups when compared to scopolamine treated group. All groups show \% DI above $50 \%$ while scopolamine group has shown significantly low value as compared to control $(p<0.01)$ (Fig. 3c \& f). Similarly, in the sample phase of long term memory task, no significant differences were observed in the total time spent exploring the two identical objects between the CGA, CHF. Ext and scopolamine treated group (Fig. $3 g$ \& j). A significant $(* p<0.05$, $* p<0.01)$ increase occurs in the test phase of long term memory in spending the time for exploration of novel object with CHF. Ext, (100 \& $200 \mathrm{mg} / \mathrm{kg})$, CGA (10 \& $30 \mathrm{mg} / \mathrm{Kg})$ and donepezil $(2 \mathrm{mg} / \mathrm{kg})$ treated groups. However, scopolamine group has shown a significant $(p<0.01)$ increase in exploration time with the familiar object compared to novel one (Fig. $3 \mathrm{~h} \& \mathrm{k}$ ). The CHF. Ext $(100,200 \mathrm{mg} / \mathrm{kg})$, CGA (10 \& $30 \mathrm{mg} / \mathrm{Kg})$ and donepezil $2 \mathrm{mg} / \mathrm{kg}$ groups have shown significant ( $p<0.05$, $\left.{ }^{* *} p<0.01\right)$ increase in \%DI, while scopolamine $1 \mathrm{mg} / \mathrm{kg}$ group has significantly $(p<0.01)$ lower $\% \mathrm{DI}$ as compared to control (Fig. 3 i \& 1 ).
Effect of isolated compounds and extract fraction on brain Cholinesterases (AChE and BChE) activity in mice

Ex vivo analysis of cholinesterase inhibitory potentials was also measured to check the cholinergic hypo function in animal model using the isolated compound CGA and CHF extract. One hour after administration of the last dose of isolated compound CGA (10 and $30 \mathrm{mg} / \mathrm{kg}$; (i.p.) and CHF. Ext $(200 \mathrm{mg} / \mathrm{kg}$; (i.p.), animals were sacrificed. Frontal cortex and hippocampal tissues were isolated in ice cold phosphate buffer and supernatants were collected from homogenized part of brain tissues at a standardized protein content of $5 \mathrm{mg} / \mathrm{ml}$. \%AChE and \%BChE activity results in frontal cortex and hippocampus of different groups of animals in Y-Maze test are given in Fig. 4. Significantly $(* * * p<$ 0.001) high AChE and BChE activity was observed in the frontal cortex and hippocampus tissues of scopolamine treated group (Fig. 4a and b). A significant decline $(* * p<$ $0.01 ; * * * 0.001)$ in $\% \mathrm{AChE}$ and BChE activity was observed in Donepezil treated group (standard control group) in the cortex and hippocampus regions respectively. The \% AChE activity in the cortex and hippocampus tissues of normal control group were significantly different $\left({ }^{* * * * *} p<\right.$ $0.001 ; * * 0<0.01$ ) from scopolamine treated group.

$\% \mathrm{AChE}$ activities in frontal cortex and hippocampus of different groups of animals in Novel object recognition test are given in Fig. 4c. Percent AChE and BChE activity in the cortex and hippocampus of scopolamine treated group was significantly $\left({ }^{* * *} p<0.001\right)$ higher than that of the control group. \%AChE (A) and BChE (Fig. 4c \& d) activity in the cortex and hippocampus of Donepezil treated groups were significantly $\left({ }^{* * * *} p<0.001\right.$; *** $p<$ 0.01 ) lower as compared to scopolamine treated group. The results of \% AChE and BChE activity of CGA and $\mathrm{CHF}$ treated groups in the cortex and hippocampus tissues were also significantly $\left({ }^{* * * *} p<0.001 ; * * p<0.01\right)$ lower when compared to scopolamine treated group.

\section{Effect of isolated compounds and extract fraction on brain DPPH free radicals scavenging activity in mice}

Results regarding ex vivo \%DPPH free radicals scavenging potential in cortex and hippocampus of different animal groups in Y-Maize test are summarized in Fig. 5a and b. \% antiradicals activity of Normal control group was significantly high $(* * * * 0.001)$ than that of Scopolamine treated group. Furthermore, Donepezil treated and test control groups like CGA and CHF showed: $39.62 \pm 4.12$, $47.85 \pm 2.11$ and $30.53 \pm 1.65 \%$ DPPH inhibition potential in cortex and $52.41 \pm 1.43,44.12 \pm 1.77$, $32.63 \pm 2.47 \%$ in hippocampus respectively.

Ex vivo \%DPPH free radicals scavenging potential in cortex and hippocampus of different animals groups in Novel object recognition test are summarized in Fig. 5c \& d. Percent DPPH inhibition activity in the cortex and hippocampus of normal control group was significantly 


\section{Short-term memory}

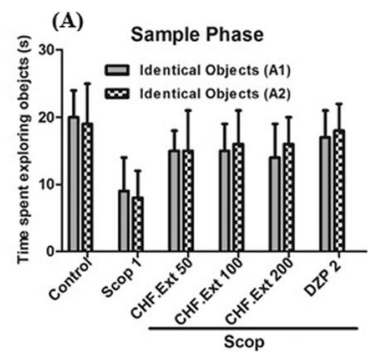

(D)

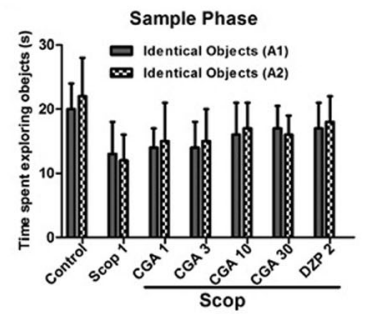

Long-term memory

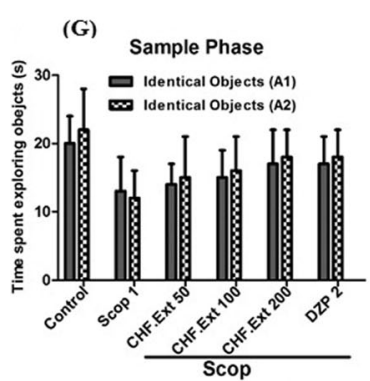

(J)

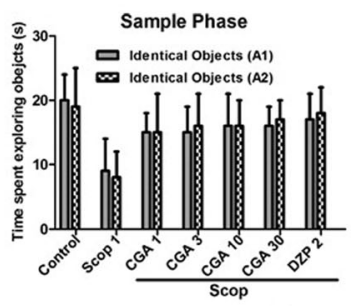

(B)

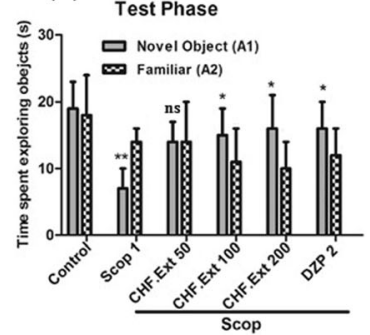

(E)

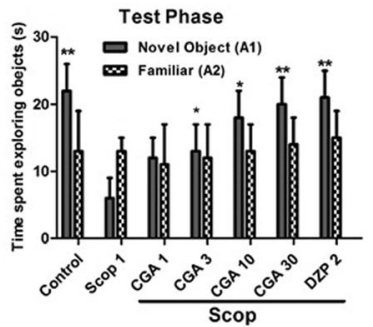

(H)

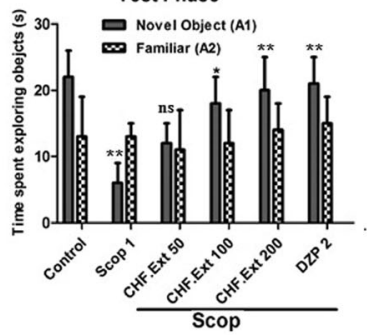

(K)

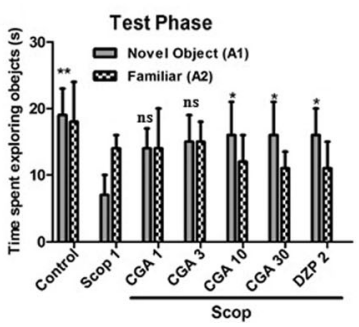

(C)

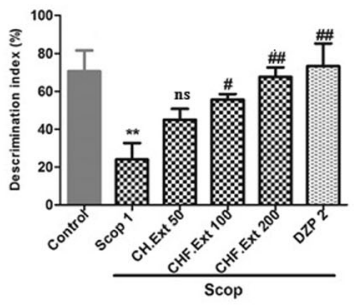

(F)

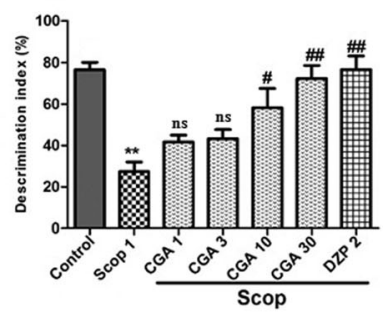

(I)

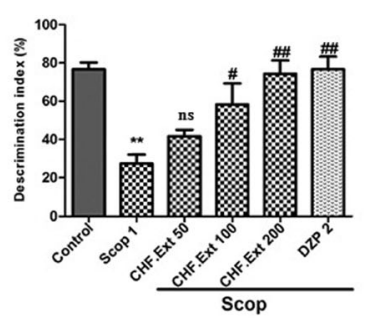

(L)

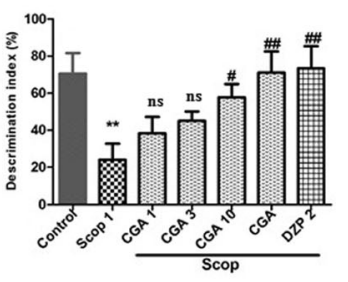

Fig. 3 Effect of CHF. Ext and isolated compound (CGA) of E. umbellata Thunb. on mice in behavioural NORT \{(a) Time spent in the sample phase (b) Time spent in the test phase (c) \% Discrimination index were recorded in CHF. Ext (50, $100 \mathrm{and} 200 \mathrm{mg} / \mathrm{kg}$ ) treated groups versus scopolamine (Scop. $1 \mathrm{mg} / \mathrm{kg}$ ) treated group and (d) Time spent in the sample phase (e) Time spent in the test phase (f) \% Discrimination index were recorded in isolated compound chlorogenic acid (CGA: 1, 3, 10 and $30 \mathrm{mg} / \mathrm{kg}$ ) treated groups versus scopolamine (Scop. $1 \mathrm{mg} / \mathrm{kg}$ ) treated group for assessment of short-term memory in mice model in behavioral NORT; (g) Time spent in the sample phase (h) Time spent in the test phase (i) \% Discrimination index were recorded in CHF. Ext (50, 100 and $200 \mathrm{mg} / \mathrm{kg}$ ) treated groups versus scopolamine (Scop. $1 \mathrm{mg} / \mathrm{kg})$ treated group and (j) Time spent in the sample phase (k) Time spent in the test phase (I) \% Discrimination index were recorded for isolated compound chlorogenic acid (1, 3, 10 and $30 \mathrm{mg} / \mathrm{kg}$ ) treated groups versus scopolamine (Scop. $1 \mathrm{mg} / \mathrm{kg}$ ) treated group for assessment of long-term memory in mice model in behavioral NORT\}

$\left({ }^{* * * *} p<0.001\right)$ higher than that of scopolamine treated group. Donepezil, CGA and CHF treated groups showed significantly higher \% anti-radicals activities: $55.41 \pm$ $4.55,51.43 \pm 2.88,45.74 \pm 2.47$ in cortex $(C)$ and $59.58 \pm$ $4.11,65.36 \pm 1.45,62.54 \pm 3.52$ in hippocampus (D) respectively as compared to standard group.

\section{Molecular docking validation of isolated compounds for} anticholinesterases (AChE \& BChE)

To study the molecular docking of cholinesterase (AChE \& BChE) inhibition; binding analyses of the isolated compounds were performed on a GOLD suit v5.6.3. For this purpose, crystal structures of TcAChE in complex 

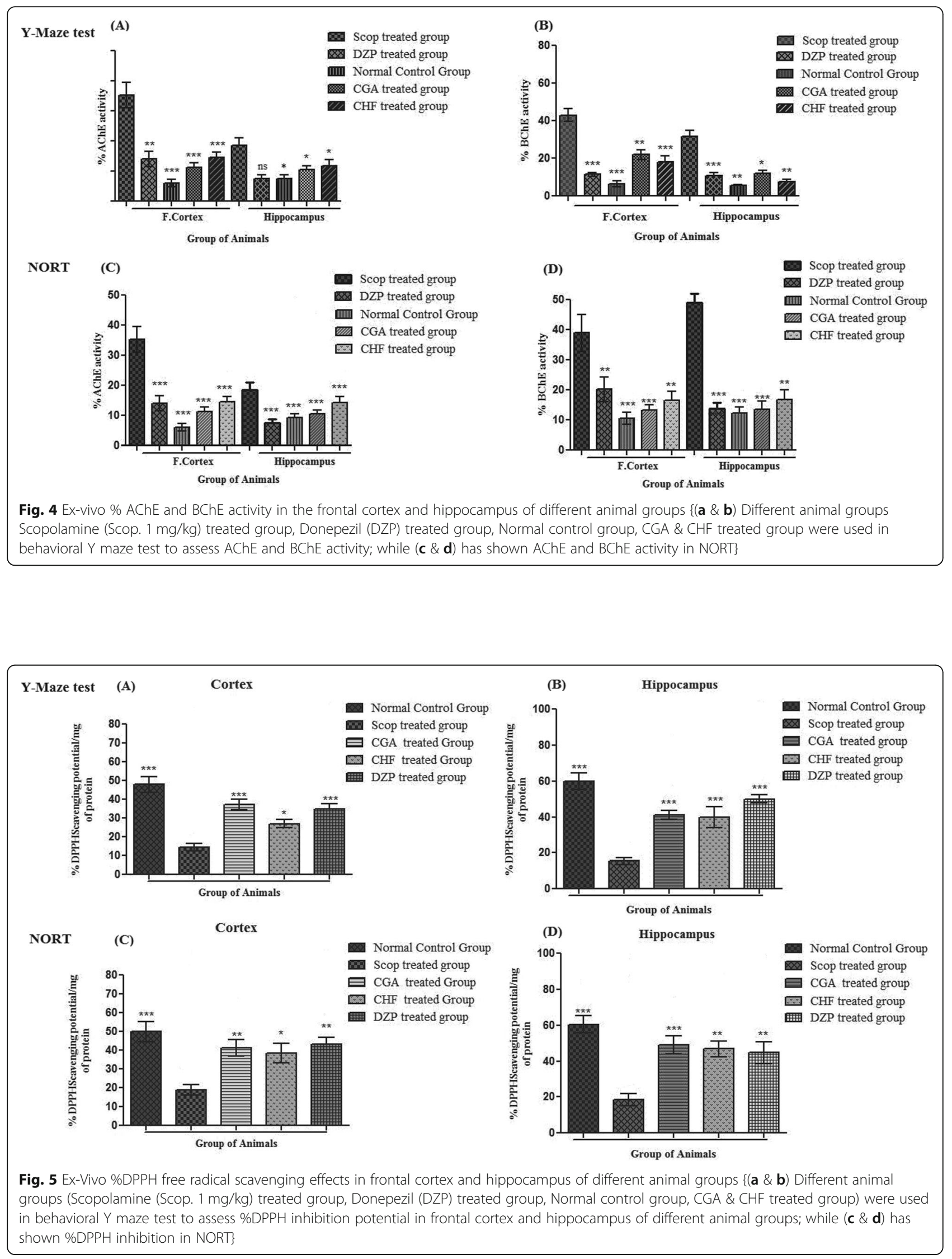
with donepezil from Tetronarce californica (PDB ID: $1 \mathrm{EVE})$ and $h \mathrm{BChE}$ in complex with tacrine (PDB ID: 4BDS) from Homo sapiens were used as receptors. The docking pose of most active compound chlorogenic acid superimposed onto donepezil inside the binding cavity of $1 E V E$ is shown in Fig. 6a. Analysis of binding modes indicates similar binding orientations for chlorogenic acid and donepezil in the active gorge of the receptor protein. Upon visual inspection (Fig. 6b \& c), we can observe interactions such as $\pi-\pi$ stacking (TRP83 to phenolic ring), conventional hydrogen bonding (TYR129 to $\mathrm{OH}$ of phenolic ring), pi-lone pair (PHE329 to $\mathrm{C}=\mathrm{O}$ group of caffeoyl moiety), and numerous van der Waals attractions for the best docking pose of chlorogenic acid (Gold fitness score $=62.69$ ).

For studying the mechanism of inhibition for human $\mathrm{BChE}$, the crystal structure with PDB ID of 4BDS was used as target protein. The mechanism of $\mathrm{BChE}$ inhibition by chlorogenic acid was studied by viewing its interactions in the active gorge of human BChE (PDB ID: $4 \mathrm{BDS}$ ) as the enzyme model. The structural features of the most active compound chlorogenic acid suggest that it must have interactions like hydrophilic and hydrophobic in the active site of the enzyme. Upon visual inspection of the best docked pose (Fig. $5 \mathrm{~d} \&$ e), chlorogenic acid can be seen to bind hydrophobically ( $\pi-\pi$ stacking) with amino acid residues LEU283, PHE326, and TRP228. Numerous hydrogen bonding interactions between amino acids (TYR125, SER195, and GLU194) and hydroxyl groups of chlorogenic acid also seems to contribute to stability of chlorogenic acid-BChE complex.

The docking posture of the active ellagic acid superimposed onto donepezil in the inner surface of the binding cavity of 1EVE is shown in Fig. 6f. Examination of

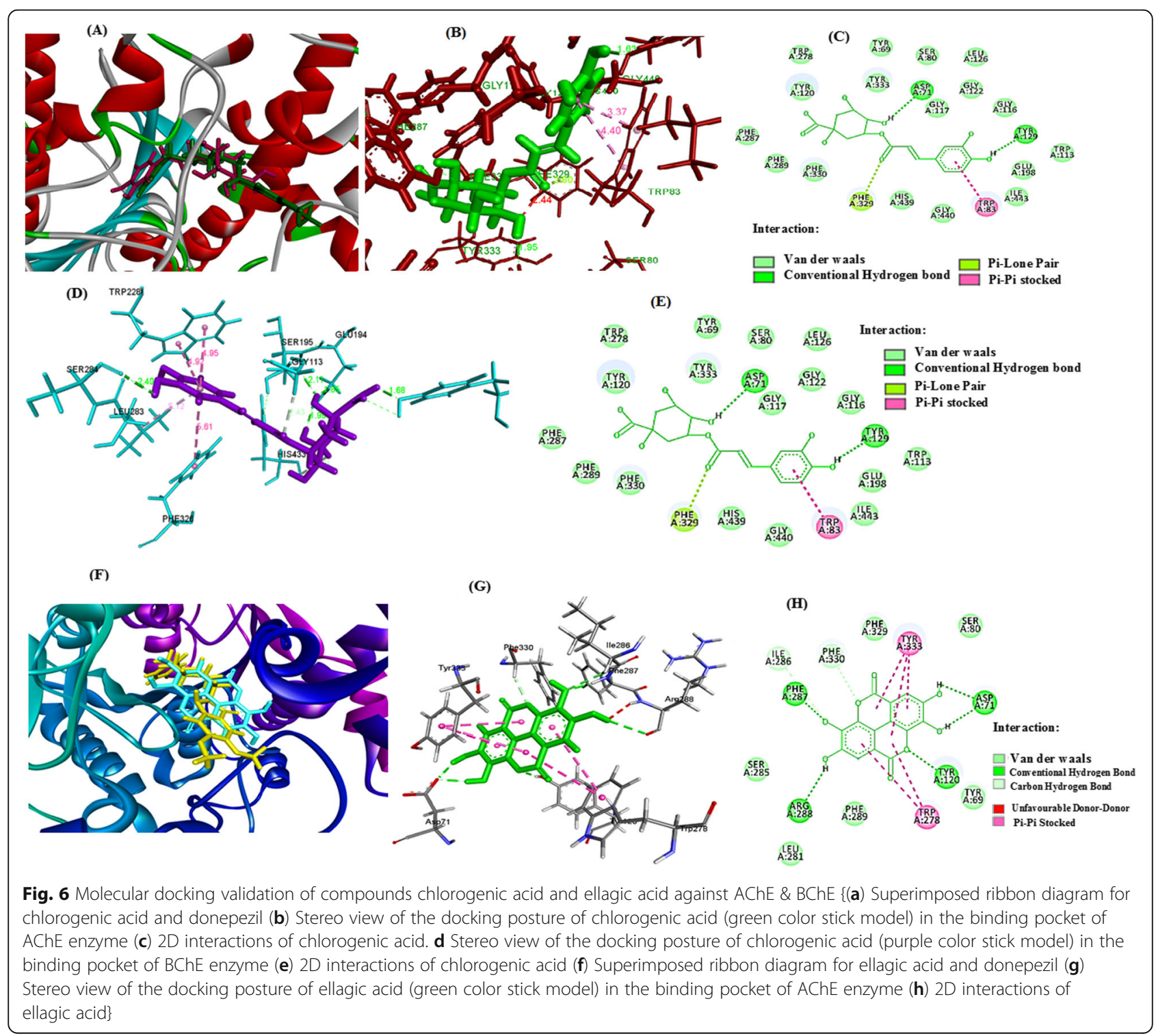


different binding modes indicates similar binding coordination for ellagic acid and donepezil in the active pocket of the receptor protein. Upon visual inspection (Fig. $6 \mathrm{~g}$ $\& \mathrm{~h})$, different interactions can be seen such as $\pi-\pi$ stacking (TRP278, TYR333), conventional hydrogen bonding (TYR120, ARG288, PHE287, ASP71 to OH of phenolic ring), carbon hydrogen bond interactions (PHE330, ILE286), unfavorable donor-donor interaction (ARG288 to OH group) and various number of van der Waals attractions for the best docking pose of ellagic acid (Gold fitness score $=55.24$ ).

The Gold score values and energy of ligands of isolated compounds are presented in Table 4. The chlorogenic acid and ellagic acid have higher Gold score values with highest cholinesterase inhibitory activities while, gallic acid and phloroglucinol showed weaker inhibitory activity. The more Gold Score values represent tighter binders.

\section{Discussion}

Memory is the process where experiences are documented in brain that can be used to acclimate their responses to the environment. It has great importance in some one life to define itself and their place along with normal working life. Central cholinergic system is considered to be the most important neurotransmitter involved in regulation of cognitive functions. Acetyl cholinesterase is the key enzyme responsible for acetylcholine hydrolysis which terminates the cholinergic transmission. Decrease in the cholinergic conduction is associated with cognitive dysfunction and are reported in neurodegenerative diseases such as Alzheimer's disease (AD). Literature studies have revealed that cholinesterase inhibitors might act on several therapeutic targets such as AChE enzyme that is responsible for acetylcholine hydrolysis $[41,42]$. However, there is still a need of novel AChE inhibitors with low toxicity and high penetration rate to the central nervous system. The dementing illness that has received the most attention in the past decade is $\mathrm{AD}$, while impaired cognitive functions are the major features of $\mathrm{AD}$. The only standard

Table 4 The Gold scores and energy of ligand values of cholinesterase inhibitors present in Elaeagnus umbellata Thunb. fruit

\begin{tabular}{llll}
\hline Compound & Compound name & Gold Score & Energy of ligand \\
\hline Compound-I & Chlorogenic acid & 62.69 & -10.556 \\
Compound-II & Ellagic acid & 55.24 & -6.971 \\
Compound-III & Gallic acid & 39.42 & -6.917 \\
Compound-IV & Phloroglucinol & 33.28 & -5.071 \\
\hline
\end{tabular}

The Chlorogenic acid and Ellagic acid have higher Gold score values with highest cholinesterase inhibitory activities while, Gallic acid and Phloroglucinol showed weaker inhibitory activity. The more Gold Score values represent tighter binders [40] drugs used as acetyl cholinesterase inhibitors for AD are galantamine, donepezil and rivastigmine [41]. Natural products have already demonstrated to be promising sources of functional acetyl cholinesterase (AChE) inhibitors. The standard drugs for AD treatment, galantamine and rivastigmine are alkaloids derived from plants [42]. $\mathrm{AChE}$ inhibition is also considered as a remedial strategy for other types of neuronal disorders like dementia and Parkinson's diseases [43]. There is still a need to explore new plants for new potent and enduring AChE inhibitors with low or no side effects. Many plant species from various parts of the world have been evaluated for anticholinesterase activity [44, 45].

It is obvious of our current investigational study that E. umbellata extracts displayed various bioactive constituents including alkaloids, flavonoids, glycosides, tannins, terpenoids, anthraquinones and pigments provide a significant source of secondary metabolites which play a role as cholinesterase inhibitors [21, 22, 46]. In the present study, both the chloroform extract and isolated compounds were found potent to inhibit the Acetyl cholinesterase enzyme and restoring the cholinergic functions. This property tends to allow more retention of acetylcholine in the brain, which is important for the cognitive function, learning and memory. The present study demonstrates the beneficial effect of chloroform extract and chlorogenic acid of E. umbellata on scopolamine-induced amnesia. Oral suspension of the extracts and isolated compound was fed to the animals used in rodent models of memory and learning, viz. Y maze and Novel object recognition test. Behavioural study was further confirmed by estimation of the brain biochemical such as brain cholinesterases (AChE and $\mathrm{BChE}$ ) activity and DPPH free radicals scavenging activity in mice. Y maze spontaneous alteration test is used for studying working memory and exploration of the animals. The test is based on the willing of the animals to explore new environment. The normal animals will explore the new arm, the animals whose memory is not working properly will again enter the old arm previously explored. This gave less number of spontaneous explorations as compared to normal animals. In this study, the chloroform extract and chlorogenic acid significantly decreased the number of alternate arm returns as compared to control. Furthermore, the CHF. Ext and CGA also significantly increased spontaneous alternation performance which was parallel with reported study $[47,48]$.

Novel object recognition test is use for studying both short and long term memory. The general principle of novel object recognition test is based on exploring new object. The rodents spend more time with unfamiliar object as compared to familiar object. In this study, the CHF. Ext and CGA caused increase exploration of the 
novel object compared to the familiar object and were comparable to reference drug donepezil. In NORT, the increase of the \%DI and novel object exploration time in mice treated with CHF. Ext and CGA suggested improvement of learning and memory. However, Scopolamine significantly decreased the discrimination index, indicating impairment of learning and memory. This effect was reversed by E. umbellata CHF. Ext and isolated compound CGA, significantly increased DI and novel object exploration time, indicating that E. umbellata fruit possesses memory enhancing activity. These findings were further supported by their potential to inhibit $\mathrm{AChE}$ and BChE enzymes both in vitro and in vivo which was also validated by in silico molecular docking study. Current results were in agreement with a previous study of Zahra R et al [48].

The high potency and anti-amnesic potential of CHF. Ext fraction is due to the presence of isolated compound chlorogenic acid which has strong neuroprotective effects on learning and memory impairment that may provide novel leads for the development of $\mathrm{AChE}$ inhibitors [27]. CGA is the key polyphenolic constituent that exhibits cardio-protective effects, inhibitory role against lipid hyper oxidation, anti-tumour activity and free radical scavenging potential [49]. Specifically, the antianxiety effects of CGA are associated with its antioxidant potential that significantly suppresses the second restraint-induced release of serotonin from the rat hippocampus, suggesting that CGA contributes to relaxation of restraint stress [50]. In addition, chlorogenic acid derivatives have shown neuroprotective effects on hydrogen peroxide and amyloid beta $(\mathrm{A} \beta)$ - induced cell death in PC12 and SH-SY5Y cells [29].

To the best of our knowledge, there was no reported neuroprotective study on E. umbellata. Therefore this is the first study to report important phyto-constituents (chlorogenic acid, ellagic acid, gallic acid and phloroglucinol) in E. umbellata fruits which are responsible for both in-vitro and in-vivo anti-cholinesterase activity and in-vivo anti-amnesic potential.

\section{Conclusion}

The E. umbellata fruit was subjected to extraction and fractionation. The fractions were tested for different biological potentials. Based on in vitro results chloroform fraction was subjected to isolation of responsible compounds that resulted in isolation of compound I to IV. Based on literature finding and our in vitro and in vivo results compound-I was further investigated to achieve the desire goal. It showed significant antiamnesic activity as assessed by behavioral tests using Y maze and Novel object recognition test in mice animal model. It is concluded that E. umbellata is a rich source of potential bioactive compounds which exhibited potent in-vitro and in-vivo neuro-protective activities. E. umbellata fruits extract/fractions and isolated compound chlorogenic acid exhibited a cognitive-enhancing effect by reversing scopolamine-induced learning and memory deficits. Thus E. umbellata fruits could be recommended for controlling memory impairments and neurological disorders. However, further work is required to investigate their exact mechanism and cellular pathways which are contributing in this cascade.

\section{Supplementary information}

Supplementary information accompanies this paper at https://doi.org/10. 1186/s12906-020-02942-3.

Additional file 1: Table S1. Total phenolic and flavonoid contents in extract/fractions of Elaeagnus umbellata fruit. Table S2. \% Choline esterase (AChE and BChE) inhibition potential of extract/fractions of Elaeagnus umbellata fruit. Table S3. \% Cholinesterase (AChE and BChE) inhibition potential of compound I-IV at various concentrations. Table S4. \% DPPH and ABTS free radical scavenging activity of isolated compounds I-IV. Table S5. The chemical shifts of Compound-I in solvent MeOD. Table S6. The chemical shifts of compound-IV in solvent MeOD. Figure S1. Total Phenolic and Flavonoids Content of CHF.Ext and their linear correlation with anticholinesterase enzymes. Figure S2. Structural formulas of isolated compounds I-IV and standard drug donepezil. Figure S3. FTIR spectrum of compound-I. Figure S4. FAB-Mass of compound-I. Figure S5. ${ }^{1} \mathrm{H}-(500 \mathrm{MHz}$.) NMR spectrum of compound-I. Figure S6. ${ }^{13} \mathrm{C}-\mathrm{NMR}(126 \mathrm{MHz})$ spectrum of compound-I. Figure S7. ${ }^{1} \mathrm{H} \mathrm{NMR}$ (CHLOROFORM-d, 500MHz) of compound-II. Figure S8. ${ }^{13} \mathrm{C}$ NMR (Chloroform-d, 100MHz) of compound-II. Figure S9. EIMS of Compound-II. Figure S10. ${ }^{1} \mathrm{H}$ NMR (METHANOL- $\left.\mathrm{d}_{4}, 500 \mathrm{MHz}\right)$ of compound-III. Figure S11. ${ }^{13} \mathrm{C}$ NMR (METHANOL- $\mathrm{d}_{4}, 100 \mathrm{MHz}$ ) of compound-III. Figure S12. EIMS spectra of compound-III. Figure S13. FTIR spectra of compound-IV. Figure S14. $1 \mathrm{H}-(500 \mathrm{MHz})$ of compound-IV. Figure S15. ${ }^{13} \mathrm{C}-\mathrm{NMR}(126$ $\mathrm{MHz}$ ) of compound-IV. Figure S16. EIMS of compound-IV. Figure S17. Escape Latency (seconds) Results of Y-Maze test in different animals groups.

\section{Abbreviations}

Aq.Ext: Aqueous fraction; AChE: Acetylcholine esterase; ABTS2: 2'-Azino-bis (3ethylbenzothiazoline-6-sulfonic acid); AD: Alzheimer's Disease;

Ach: Acetylcholine; But.Ext: n-Butanol; BChE: Butyrylcholine esterase; CHF.Ext: Chloroform fraction; C13NMR: Carbon-13 Nuclear Magneticresonance; CGA: Chlorogenic acid; DPPH 2: 2-Diphenyl, 1, picrylhydrazyl; E. umbellata: Elaeagnus umbellata; EtAc.Ext: Ethyl acetate fraction; FTIR: Fourier Transform Infrared-spectroscopy; FAB-MS: Fast Atom Bombardment Mass Spectrum; Hex.Ext: $n$-hexane fraction; HNMR: $\mathrm{H}^{+}$-Nuclear Magnetic-resonance; $I C_{50}$ : Median inhibitory concentration; i.p.: Intraperitoneal; Met.Ext: hydro methanolic extract; NORT: Novel object recognition Test; p.o.: Per oral; SEM: Standard error mean; STM: Short term memory; SAP: Spontaneous Alternation-performance

\section{Acknowledgements}

The authors are grateful to Prof. Mehboob-ur-Rahman, Govt. Post Graduate College, Mata Swat, Pakistan for the identification of plant. The authors are also grateful to Higher Education commission of Pakistan for providing support in instruments (Project No: 20-2515/R\&D/HEC and 20-3425/ R\&D/HEC).

\section{Authors' contributions}

NN carried out experimental work, plants collection, and literature search and manuscript preparation. NK helped in in vivo experimental work. AL, SA \& ZU carried out spectral analysis and molecular docking. MZ supervised the research work. MN and $M Z$ refined the manuscript for publication. All authors have read and approved the manuscript. 


\section{Availability of data and materials}

The data presented in this manuscript belong to the PhD work of Dr. Nausheen Nazir and has not been deposited in any repository yet. However, the materials are available to the researchers upon request.

\section{Ethics approval and consent to participate}

All procedures related to the animal activities have been approved by the Departmental Animal Ethical Committee (DAEC/PHARM/2019/1) of University of Malakand and were conducted according to the UK: Animal Scientific Procedure Act (1986). These guidelines were in accordance with the internationally documented principles for laboratory used and care.

\section{Consent for publication}

Not applicable for this submission.

\section{Competing interests}

The authors declare that they have no competing interests.

\section{Author details}

'Department of Biochemistry, University of Malakand, Chakdara Dir (L), Khyber Pakhtunkhwa, Pakistan. ${ }^{2}$ Department of Botany, University of Malakand, Chakdara Dir (L), Khyber Pakhtunkhwa, Pakistan. ${ }^{3}$ Department of Pharmacy, University of Malakand, Chakdara Dir (L), Khyber Pakhtunkhwa, Pakistan. ${ }^{4}$ Department of Chemistry, University of Malakand, Chakdara Dir (L), Khyber Pakhtunkhwa, Pakistan. ${ }^{5}$ Department of Pharmacy, Sarhad University of Information Technology, Peshawar, Pakistan. ${ }^{6}$ Department of Pharmacy, COMSATS University Islamabad, Abbottabad Campus, Abbottabad, Pakistan.

\section{Received: 10 December 2019 Accepted: 4 May 2020}

\section{Published online: 12 May 2020}

\section{References}

1. Kumar K, Kumar A, Keegan RM, Deshmukh R. Recent advances in the neurobiology and neuropharmacology of Alzheimer's disease. Biomed Pharmacother. 2018;98:297-307.

2. Kuca K, Soukup O, Maresova P, Korabecny J, Nepovimova E, Klimova B, et al. Current approaches against Alzheimer's disease in clinical trials. J Braz Chem Soc. 2016;27(4):641-9.

3. Gray SL, Anderson ML, Crane PK, Breitner JC, McCormick W, Bowen JD, et al. Antioxidant vitamin supplement use and risk of dementia or Alzheimer's disease in older adults. J Am Geriatr Soc. 2008;56:291-5.

4. Vickers JC, Mitew SA, Woodhouse CM, Fernandez M, Kirkcaldie MT, Canty AJ, et al. Defining the earliest pathological changes of Alzheimer's disease. Curr Alzheimer Res. 2016;13(3):281-7.

5. Arendt T. Synaptic degeneration in Alzheimer's disease. Acta Neuropathol. 2009:118:167-79.

6. Niranjan R. Recent advances in the mechanisms of neuroinflammation and their roles in neurodegeneration. Neurochem Int. 2018;120:13-20.

7. Rahman A, Choudhary M. Bioactive natural products as a potential source of new pharmacophores a theory of memory. Pure Appl Chem. 2001;73:555-60.

8. Muller WE, Eckert A, Kurz C, Eckert G, Leuner K. Mitochondrial dysfunction: common final pathway in brain aging and Alzheimer's disease therapeutic aspects. Mol Neurobiol. 2010;41:159-71.

9. Allen RJ. Classic and recent advances in understanding amnesia. F1000Research. 2018;7:331

10. Nazir N, Karim N, Abdel-Halim H, Khan I, Wadood SF, Nisar M Phytochemical analysis, molecular docking and antiamnesic effects of methanolic extract of Silybum marianum (L.) Gaertn seeds in scopolamine induced memory impairment in mice. J Ethnopharmacol. 2018;210:198-208.

11. Ahmadi A, Roghani M, Noori S, Nahri-Niknafs B. Substituted Aminobenzothiazole derivatives of Tacrine: synthesis and study on learning and memory impairment in scopolamine-induced model of amnesia in rat. Mini-Rev Med Chem. 2019;19(77):72-8.

12. Nagy IZ. On the true role of oxygen free radicals in the living state, ageing and degenerative disorders. Ann N Y Acad Sci. 2001;928:187-91.

13. Lobo V, Patil A, Phatak A, Chandra N. Free radicals, antioxidants and functional foods: impact on human health. Pharmacogn Rev. 2010;4(8):118-26.

14. Erejuwa O, Sulaiman S, Wahab AB. Honey: a novel antioxidant. Molecules. 2012;17(4):4400-23.
15. Vina J, Lloret A, Giraldo E, Badia M, Alonso M. Antioxidant pathways in Alzheimer's disease: possibilities of intervention. Curr Pharm Des. 2011; 17(35):3861-4.

16. Abbasi AM, Khan MA, Ahmad M, Zafar M. Medicinal plant biodiversity of lesser Himalayas, Pakistan. New York, Dordrecht, Heidelberg, London: Springer; 2012.

17. Aziz MA, Adnan M, Khan AH, Shahat AA, Al-Said MS, Ullah R. Traditional uses of medicinal plants practiced by the indigenous communities at Mohmand agency, FATA, Pakistan. J Ethnobiol Ethnomed. 2018;14(1):2.

18. Sabir SM, Dilnawaz S, Imtiaz A, Hussain M, Kaleem MT. Antibacterial activity of Elaeagnus umbellata (Thunb.) a medicinal plant from Pakistan. Saudi Med J. 2007;28(2):259-63.

19. Nazir N, Zahoor M, Nisar M, Khan I, Karim N, Abdel-Halim H, et al. Phytochemical analysis and antidiabetic potential of Elaeagnus umbellata (Thunb.) in streptozotocin-induced diabetic rats: pharmacological and computational approach. BMC Complement Altern Med. 2018;18(1):332 1-16.

20. Khattak KF. Free radical scavenging activity, phytochemical composition, and nutrient analysis of Elaeagnus umbellata berry. J Med Plant Res. 2012;6: 5196-203.

21. Ghias U, Rauf A. Phytochemical screening and biological activity of the aerial parts of Elaeagnus umbellata. Sci Res Essays. 2012;7(43):3690-4.

22. Rafique N, Khan T, Shah AJ. Calcium entry blocking activity of the Elaeagnus umbellata fruit extract explains its use in diarrhea and gut spasm. Bangladesh J Pharmacol. 2016;11:585-92.

23. Syeda FA, Habib UR. Phytochemical investigations on Elaeagnus umbellata. GJSFR. 2012;12(7-B):1-7.

24. Figueira I, Menezes R, Macedo D, Costa I, Dos Santos CN. Polyphenols beyond barriers: a glimpse into the brain. Curr Neuropharmacol. 2017;15(4): 562-94.

25. Subash S, Essa MM, Al-Adawi S, Memon MA, Manivasagam T, Akbar M. Neuroprotective effects of berry fruits on neurodegenerative diseases. Neural Regen Res. 2014;9(16):1557-66.

26. Kim MJ, Lim JS, Yang SA. Component analysis and anti-proliferative effects of ethanol extracts of fruits, leaves, and stems from Elaeagnus umbellata in HepG2 cells. Korean J Food Nutr. 2016;45:828-34.

27. Kwon SH, Lee HK, Kim JA, Hong SI, Kim HC, Jo TH, et al. Neuroprotective effects of chlorogenic acid on scopolamine-induced amnesia via antiacetylcholinesterase and anti-oxidative activities in mice. Eur J Pharmacol. 2010;649(1-3):210-7.

28. Jha A, Panchal S, Shah A. Ellagic acid: insights into its neuroprotective and cognitive enhancement effects in sporadic Alzheimer's disease. Pharmacol Biochem Behav. 2018;175:33-46.

29. Kim SS, Park RY, Jeon HJ, Kwon YS, Chun W. Neuroprotective effects of 3, 5dicaffeoylquinic acid on hydrogen peroxide-induced cell death in SH-SY5Y cells. Phytother Res. 2005;19:243-5.

30. Khan FA, Ullah Z, Haider S. Phytochemicals screening and antimicrobial activities of selected medicinal plants of Khyberpakhtunkhwa Pakistan. Afr J Pharm Pharmacol. 2011;5(6):746-50.

31. Ayoub L, Hassan F, Hamid S, Abdelhamid Z, Aboudkhil S. Phytochemical screening, antioxidant activity and inhibitory potential of Ficus carica and Olea europaea leaves. Bioinformation. 2019:15:226-32.

32. Shirazi U, Khattak K, Shukri M, Nasyriq N. Determination of total phenolic, flavonoid content and free radical scavenging activities of common herbs and spices. J of Pharm and Phytochem. 2014;3(3):104-8.

33. Classics Ellman G, Courtney K, Andres V, Featherstone R. A new and rapid colorimetric determination of acetylcholinesterase activity. Biochem Pharmacol. 1961;7:88-95.

34. Brand-Williams W, Cuvelier M, Berset C. Use of a free radical method to evaluate antioxidant activity. LWT-Food Sci Technol. 1995;28(1):25-30.

35. Re R, Pellegrini N, Proteggente A, Pannala A, Yang M, Ric EC. Antioxidant activity applying an improved FBTS radical cation decolorization assay. Free Radic Biol Med. 1999:26(9/10):7-1231.

36. Barua C, Haloi A, Patowary P, Bora M, Barua A, Bordoloi M, et al. Evaluation of anti-amnestic activity of few medicinal plants against scopolamine induced amnesia. Indian J Tradit Knowl. 2015;14:581-9.

37. Hughes RN. The value of spontaneous alternation behavior (SAB) as a test of retention in pharmacological investigations of memory. Neurosci Biobehav Rev. 2004:28:497-505.

38. Mugwagwa A, Gadaga L, Pote W, Tagwireyi D. Antiamnesic effects of a Hydroethanolic extract of Crinum macowanii on scopolamine-induced memory impairment in mice. J Neurodegener Dis. 2015;2015:1. 
39. Verdonk ML, Cole JC, Hartshorn MJ, Murray CW, Taylor RD. Improved protein-ligand docking using GOLD. Proteins. 2003;52(4):609-23.

40. Dassault Systemes BIOVIA. BIOVIA discovery studio visualizer, release 17: 2.0. 16349. Dassault Systemes: San Diego; 2016.

41. Mangialasche F, Solomon A, Winblad B, Mecocci P, Kivipelto M. Alzheimer's disease: clinical trials and drug development. Lancet Neurol. 2010;9:702-16.

42. Murray A, Faraoni M, Castro M, Alza N, Cavallaro V. Natural AChE inhibitors from plants and their contribution to Alzheimer's disease therapy. Curr Neuropharmacol. 2013;11:388-413.

43. Mehta M, Adem A, Sabbagh M. New acetylcholinesterase inhibitors for Alzheimer's disease. Int J Alzheimer's Dis Article. 2012;1:1-8.

44. Mukherjee P, Kumar V, Houghton P. Screening of Indian medicinal plants for acetylcholinesterase inhibitory activity. Phytother Res. 2007;21:1142-5.

45. Karimi E, Ghorbani Nohooji M, Habibi M, Ebrahimi M, Mehrafarin A, KhalighiSigaroodi F. Antioxidant potential assessment of phenolic and flavonoid rich fractions of Clematis orientalis and clematis ispahanica (Ranunculaceae). Nat Prod Res. 2018;32(16):1991-5.

46. Veazie P, Black B, Fordham I, Howard L. Lycopene and total phenol content of autumn olive (Elaegnus umbellata) selections. Hortic Sci. 2005:40(3):883-4.

47. Lee GY, Lee C, Park GH, Jang JH. Amelioration of scopolamine-induced learning and memory impairment by a-Pinene in C57BL/6 mice. Evid Based Complement Alternat Med. 2017:2017:4926815.

48. Rabiei Z, Setorki M. Effect of hydroalcoholic Echium amoenum extract on scopolamine-induced learning and memory impairment in rats. Pharm Biol. 2018;56(1):672-7.

49. Meng S, Cao J, Feng Q, Peng J, Hu Y. Roles of chlorogenic acid on regulating glucose and lipids metabolism: a review. Evid Based Complementary Altern Med. 2013;2013:801457.

50. Bouayed J, Rammal H, Dicko A, Younos C, Soulimani R. Chlorogenic acid, a polyphenol from Prunus domestica (Mirabelle), with coupled anxiolytic and antioxidant effects. J Neurol Sci. 2007;262:77-84.

\section{Publisher's Note}

Springer Nature remains neutral with regard to jurisdictional claims in published maps and institutional affiliations.

Ready to submit your research? Choose BMC and benefit from:

- fast, convenient online submission

- thorough peer review by experienced researchers in your field

- rapid publication on acceptance

- support for research data, including large and complex data types

- gold Open Access which fosters wider collaboration and increased citations

- maximum visibility for your research: over $100 \mathrm{M}$ website views per year

At $\mathrm{BMC}$, research is always in progress.

Learn more biomedcentral.com/submissions 